\title{
Integrative Approach Based on Leaf Spray Mass Spectrometry, HPLC-DAD-MS/MS, and NMR for Comprehensive Characterization of Isoquinoline-Derived Alkaloids in Leaves of Onychopetalum amazonicum R. E. Fr.
}

\author{
Bruna R. de Lima, ${ }^{a}$ Felipe M. A. da Silva, ${ }^{\circledR} *, a, b$ Elzalina R. Soares, ${ }^{a}$ \\ Richardson A. de Almeida, ${ }^{a}$ Francinaldo A. da Silva-Filho, ${ }^{a}$ Andersson Barison, ${ }^{c}$ \\ Emmanoel V. Costa, ${ }^{b}$ Hector H. F. Koolen, ${ }^{\circledR d}$ Afonso D. L. de Souza ${ }^{a, b}$ and \\ Maria Lúcia B. Pinheiro ${ }^{a, b}$ \\ ${ }^{a}$ Central Analítica-Centro de Apoio Multidisciplinar (CAM), \\ Universidade Federal do Amazonas (UFAM), 69077-000 Manaus-AM, Brazil \\ ${ }^{b}$ Departamento de Química, Universidade Federal do Amazonas (UFAM), \\ 69077-000 Manaus-AM, Brazil \\ 'Laboratório de RMN, Universidade Federal do Paraná(UFPR), 81531-990 Curitiba-PR, Brazil \\ ${ }^{d}$ Grupo de Pesquisa em Metabolômica e Espectrometria de Massas, \\ Universidade do Estado do Amazonas (UEA), 69050-010 Manaus-AM, Brazil
}

\begin{abstract}
Onychopetalum is an Amazonian botanical genus close-related with Bocageopsis and Unonopsis, whose species are used in traditional medicine. Although these genera are widely investigated from the phytochemical viewpoint, the knowledge about Onychopetalum remains almost unexplored. In order to perform a comprehensive characterization of isoquinoline-derived alkaloids from Onychopetalum amazonicum, an integrative approach based on the alkaloid profile analysis by leaf spray mass spectrometry (LS-MS), followed by a robust dereplication through highperformance liquid chromatography coupled with diode array detector and atmospheric pressure chemical ionization tandem mass spectrometry, (HPLC-DAD-APCI-MS/MS) and nuclear magnetic resonance (NMR) analysis was adopted. LS-MS allowed the tentative identification of reticuline, norjuziphine, nornuciferine, $O$-methylisopiline, nuciferine, $\mathrm{N}$-methyl- $\mathrm{O}$-methylisopiline, anonaine, and $N$-methylanonaine. HPLC-DAD-MS/MS analysis supported the tentative identification of $N$-methylasimilobine, asimilobine, norushinsunine, $N$-methylisopiline, isopiline, liriodenine, and lysicamine. Moreover, the integration of MS and NMR data allowed the additional identification of stepholidine and isocorypalmine. The applied integrative approach proposed herein enabled a comprehensive analysis of the alkaloid content from the O. amazonicum, showing to be a useful strategy for the dereplication of isoquinoline-derived alkaloids.
\end{abstract}

Keywords: Annonaceae, dereplication, isocorypalmine, leaf spray mass spectrometry, stepholidine

\section{Introduction}

Onychopetalum, the smaller Annonaceae genus, comprises only two species (Onychopetalum amazonicum R. E. Fr. and Onychopetalum periquino (Rusby) D. M. Johnson \& N. A. Murray). These species are characterized as trees $(8-30 \mathrm{~m})$ and present restricted distribution within the Amazon Region. ${ }^{1}$ Onychopetalum, along with Unonopsis and Bocageopsis are considered botanically

*e-mail: felipemas@ufam.edu.br close genera, being this close relationship supported by phylogenetic and phytochemical researches. ${ }^{1,2}$ Some species belonging to these genera are used in traditional medicine, e.g., U. stipitata and U. veneficiorum, whose leaves are used to treat age-related cognitive disorders by indigenous people. ${ }^{3}$ From the phytochemical viewpoint, Unonopsis and Bocageopsis are promising sources of bioactive isoquinoline-derived alkaloids, ${ }^{4,5}$ while the alkaloidal composition in Onychopetalum remains almost unexplored. For $O$. amazonicum, data about the alkaloid content is scarce, with a single report of the isolation of an 
azafluorenone alkaloid from trunk wood, named onychine. ${ }^{6}$ In addition, its terpene content for leaves, twigs and trunk bark was previously reported. ${ }^{2,7}$

Key fragmentation recognition of isoquinoline-derived alkaloids (e.g., aporphine, tetrahydroprotoberberine, and benzylisoquinoline skeletons) via collision-induced dissociation (CID) has provided a fast and safe way to access these biologically active compounds in complex matrices. ${ }^{4,5}$ Advances on the gas-phase ion chemistry of isoquinoline-derived alkaloids were recently reported to the oxoaporphine ${ }^{8}$ and $N$-formylaporphine classes, ${ }^{9}$ thus providing complementary information to these alkaloids dereplication.

Ambient ionization mass spectrometry (AIMS) techniques, including desorption electrospray ionization (DESI), direct analysis in real time (DART) and leaf spray (LS) have been demonstrated to be rapid and low-cost sampling methods for direct analysis of complex mixtures, without sample preparation, being useful to the screening of organic compounds of plant origin, in special hydrophilic bioactive compounds. ${ }^{10,11}$ Although less sensitive than mass spectrometry (MS), nuclear magnetic resonance (NMR) provides a powerful complementary technique for confirmation of main metabolites in plant extracts. ${ }^{12,13}$ In an integrative way, these techniques enable several analytical possibilities, whether in the prior recognition of complex matrices or seeking pharmacologically active substances. ${ }^{14,15}$

Thus, the aim of the present work was to perform a comprehensive characterization of isoquinoline-derived alkaloids from leaves of $O$. amazonicum. To achieve this goal, an integrative approach comprising analyses by leaf spray mass spectrometry (LS-MS), high-performance liquid chromatography coupled with diode array detector and tandem mass spectrometry (HPLC-DAD-MS/MS), and nuclear magnetic resonance (NMR) spectroscopy was applied.

\section{Experimental}

\section{Plant material}

Leaves of Onychopetalum amazonicum R. E. Fr. (Annonaceae) were collected in March 2014 at the Adolpho Ducke Forest Reserve (26 km along the AM-010 highway, in the city of Manaus, Amazonas state, Brazil, 2॰59'15.9'S 59॰55'35.5’W), from a specimen previously catalogued during the Flora project. ${ }^{16}$ The access to genetic heritage was registered at Sistema Nacional de Gestão do Patrimônio Genético e do Conhecimento Tradicional Associado (SisGen) under the code No. AE0F182. A voucher (No. 218341) was deposited in the herbarium of the Instituto Nacional de Pesquisas da Amazônia (INPA). The material was immediately dried over ambient temperature (ca. $20^{\circ} \mathrm{C}$ ) during 20 days.

\section{Leaf spray mass spectrometry (LS-MS) analysis}

The home-built LS-MS interface was achieved through the substitution of the housing for a default Db15 male connector to disable the atmospheric pressure ionization (API) interlocks (Figure 1). ${ }^{17}$ To allow the easy change between different API sources (electrospray ionization-ESI or atmospheric pressure chemical ionization-APCI) and LS, a jumper to bypass the interlock was created between sockets 9 and 10, and a $2 \mathrm{kOhm}$ resistor was attached directly between sockets 7 and 8 , generating the source recognition through the ESI source ID read back voltage. This configuration was tested with both, LCQ Fleet (ion trap) and TSQ Quantum Access (triple quadrupole) mass spectrometers (Thermo-Fisher, CA, San Jose).

The MS and $\mathrm{MS}^{2}$ measurements of LS were performed with the TSQ Quantum Access mass spectrometer. Mass spectra were acquired in a continuous monitoring mode. Dried leaves were cut into a triangle-shaped piece (base and height of $10 \mathrm{~mm}$ each) and held by a metal clip at a distance of $10 \mathrm{~mm}$ from the mass spectrometer inlet (Figure 1). High voltage $(4.5 \mathrm{kV}$, positive polarity) was applied directly to the plant tissue after wetting it with approximately $10 \mu \mathrm{L}$ of MeOH HPLC grade in order to generate a spray of charged droplets carrying endogenous chemicals toward the inlet of the mass spectrometer. MS analytical conditions were: capillary voltage, $20 \mathrm{~V}$; capillary temperature, $200{ }^{\circ} \mathrm{C}$; tube lens, $115 \mathrm{~V}$; scan range: $100-500 \mathrm{~m} / \mathrm{z}$. Argon (Ar) was used as collision gas with collision energies ranging from 20 to $30 \mathrm{eV}$.

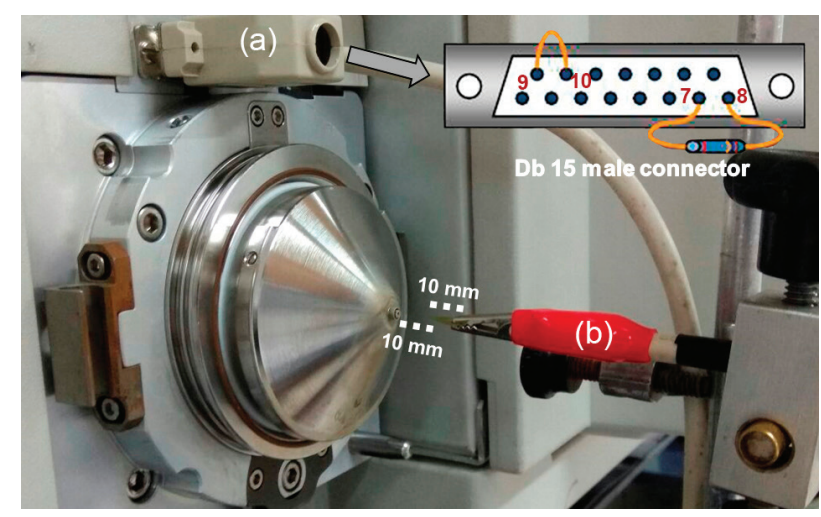

Figure 1. Home-built LS-MS interface with a Db15 male connector prepared to defeat the API interlock and promote ESI source recognition (a). O. amazonicum leaf cut in triangle-shaped pieces (base and height of $10 \mathrm{~mm}$ each) and held by a high voltage connector at $10 \mathrm{~mm}$ of distance from the mass spectrometer inlet (b). 


\section{Alkaloid extraction}

The alkaloid fraction was obtained according to a previously reported methodology. ${ }^{5}$ After dried, the plant material was powdered with a knife mill. The powdered leaves $(2 \mathrm{~g})$ were vigorously stirred using a vortex mixer for 1 min with a mixture of $10 \%$ ammonium hydroxide $\left(\mathrm{NH}_{4} \mathrm{OH}\right)$ aqueous solution $(20 \mathrm{~mL})$ and dichloromethane $\left(\mathrm{CH}_{2} \mathrm{Cl}_{2}\right)(20 \mathrm{~mL})$ in a glass container. The organic phase was transferred to another glass container and vigorously stirred $(1 \mathrm{~min})$ with a $10 \%$ acetic acid $\left(\mathrm{CH}_{3} \mathrm{CO}_{2} \mathrm{H}\right)$ aqueous solution $(20 \mathrm{~mL})$. After, the aqueous phase was separated and treated with $\mathrm{NH}_{4} \mathrm{OH}$ until $\mathrm{pH} 10$ was achieved. Then, this phase was extracted under vigorous stirring (1 min) with $\mathrm{CH}_{2} \mathrm{Cl}_{2}(20 \mathrm{~mL})$. The organic phase was dried over anhydrous sodium sulfate, transferred to a new container and the solvent evaporated to dryness under a nitrogen gas stream, yielding the crude alkaloid fraction $(8.2 \mathrm{mg}$, $0.41 \%)$.

HPLC-DAD-MS/MS and high-resolution mass spectrometry (HR-MS) analysis

The alkaloid fraction was diluted to $1 \mathrm{mg} \mathrm{mL}^{-1}$ in $\mathrm{MeOH}$ and analyzed (10 $\mu \mathrm{L}$, injection volume) with an Accela HPLC system (Thermo Scientific, Waltham, MA, USA) equipped with a Phenomenex Luna C18 column $(5 \mu \mathrm{m}, 150 \times 4.6 \mathrm{~mm}$ internal diameter, i.d.) (Torrance, CA, USA). The mobile phase consisted of $0.1 \%$ trifluoroacetic acid aqueous solution (A) and $\mathrm{MeOH}(\mathrm{B})$. Elution was performed using a flow of $1 \mathrm{~mL} \mathrm{~min}^{-1}$ and through a gradient of $20 \%$ B to $80 \%$ B over 14 min, followed by $10 \mathrm{~min}$ at $80 \% \mathrm{~B}$. UV spectra were registered from 200 to $400 \mathrm{~nm}$. The outlet from the diode array detector (DAD) was connected through a split valve (flow of $300 \mu \mathrm{L} \mathrm{min}{ }^{-1}$ ) to a TSQ Quantum Access triple quadrupole mass spectrometer (Thermo Scientific, Waltham, MA, USA). Ionization was performed with an APCI source operating at positive ion mode. The ionization settings were as follows: discharge current, $5 \mu \mathrm{A}$; vaporizer temperature, $350{ }^{\circ} \mathrm{C}$; sheath gas pressure, 35 arbitrary unit (arb); ion sweep gas pressure, $0.0 \mathrm{arb}$; auxiliary gas pressure, $15 \mathrm{arb}$; capillary temperature, $250{ }^{\circ} \mathrm{C}$; tube lens offset, $112 \mathrm{~V}$; skimmer offset, $0 \mathrm{~V}$; mass range, $\mathrm{m} / \mathrm{z}, 120$ to 800; collision energy, $30 \mathrm{eV}$. All solvents used for chromatography and MS experiments were HPLC grade purchased from Tedia (Fairfield, OH, USA), and the water was purified by a Milli-Q system (Millipore, Bedford, MA, USA).

For the HR-MS analysis, the peaks corresponding to the tetrahydroprotoberberine alkaloids were collected in HPLC-DAD-MS/MS experiment partially deviated to a collector, and subjected to a quadrupole time-of-flight (Q-TOF) mass spectrometer (Impact HD, Bruker Daltonics, Billerica, MA, USA), equipped with an ESI source, operating at positive ion mode. The ESI conditions were: capillary voltage, $4500 \mathrm{~V}$; nebulizer pressure $\left(\mathrm{N}_{2}\right), 3.0$ bar; dry gas flow $\left(\mathrm{N}_{2}\right), 10.0 \mathrm{~L} \mathrm{~min}{ }^{-1}$; dry heater temperature, $200{ }^{\circ} \mathrm{C}$; mass range, $m / z$ 100-1000.

\section{NMR analysis}

For analysis by one-dimensional (1D) and twodimensional (2D) nuclear magnetic resonance (NMR) spectroscopy, an amount of $6 \mathrm{mg}$ of the crude alkaloid fraction was solubilized in $600 \mu \mathrm{L}$ of $\mathrm{CD}_{3} \mathrm{OD}$ (Cambridge Isotope, Tewksbury, MA, USA), filtered and placed into an NMR tube. 1D and 2D NMR spectroscopy analysis were performed with an AVANCE III HD 500 NMR spectrometer (Bruker, Billerica, MA, USA), operating at 11.75 T, observing ${ }^{1} \mathrm{H}$ at 500.13 and ${ }^{13} \mathrm{C}$ at $125.76 \mathrm{MHz}$. All chemical shifts $(\delta)$ are given in ppm relative to the solvent signal, and the coupling constants $(J)$ are given in $\mathrm{Hz}$.

\section{Results and Discussion}

\section{Alkaloidal profile by LS-MS}

The positive LS-MS mass spectrum of $O$. amazonicum leaves (Figure 2a) displayed protonated molecule ions at $m / z 328$ (100\% relative abundance), $342(64 \%)$, $282(47 \%), 266(24 \%), 326(19 \%), 312(20 \%), 296(12 \%)$, $330(12 \%), 286(8 \%)$, and $280(5 \%)$, all even values, an indicative of protonated alkaloids. The $\mathrm{MS}^{2}$ spectra of the ions at $m / z$ 286, 328, 342, and 330, presented high mass losses commonly observed in tetrahydroprotoberberine and benzylisoquinoline alkaloids, ${ }^{5}$ with base peaks at $m / z, 178$ (precursors $m / z, 328$ and 342; Figures S8 and S10, Supplementary Information (SI) section), 192 (precursor $m / z$ 330; Figure S9, SI section), and 107 (precursor $m / z$ 286; Figure S4, SI section).

The fragment ion at $m / z, 178$ is consistent with the product formed via a retro-Diels-Alder (RDA) ring opening ${ }^{18}$ for the tetrahydroprotoberberine alkaloids containing methoxyl and a hydroxyl group at the A ring (Figure 3a). In addition, the neutral loss of $150 \mathrm{Da}$ (precursor $\mathrm{m} / \mathrm{z}$ 328; Figure S8, SI section) suggest the presence of methoxyl and hydroxyl groups at D ring, while the loss of $164 \mathrm{Da}$ (precursor $\mathrm{m} / \mathrm{z}, 342$; Figure S10, SI section) is in accordance with two methoxyl groups at $\mathrm{D}$ ring.

Although the fragmentation patterns observed to the protonated molecules at $m / z 328$ and 342 have been previously described in Unonopsis and Bocageopsis 
(a)

328

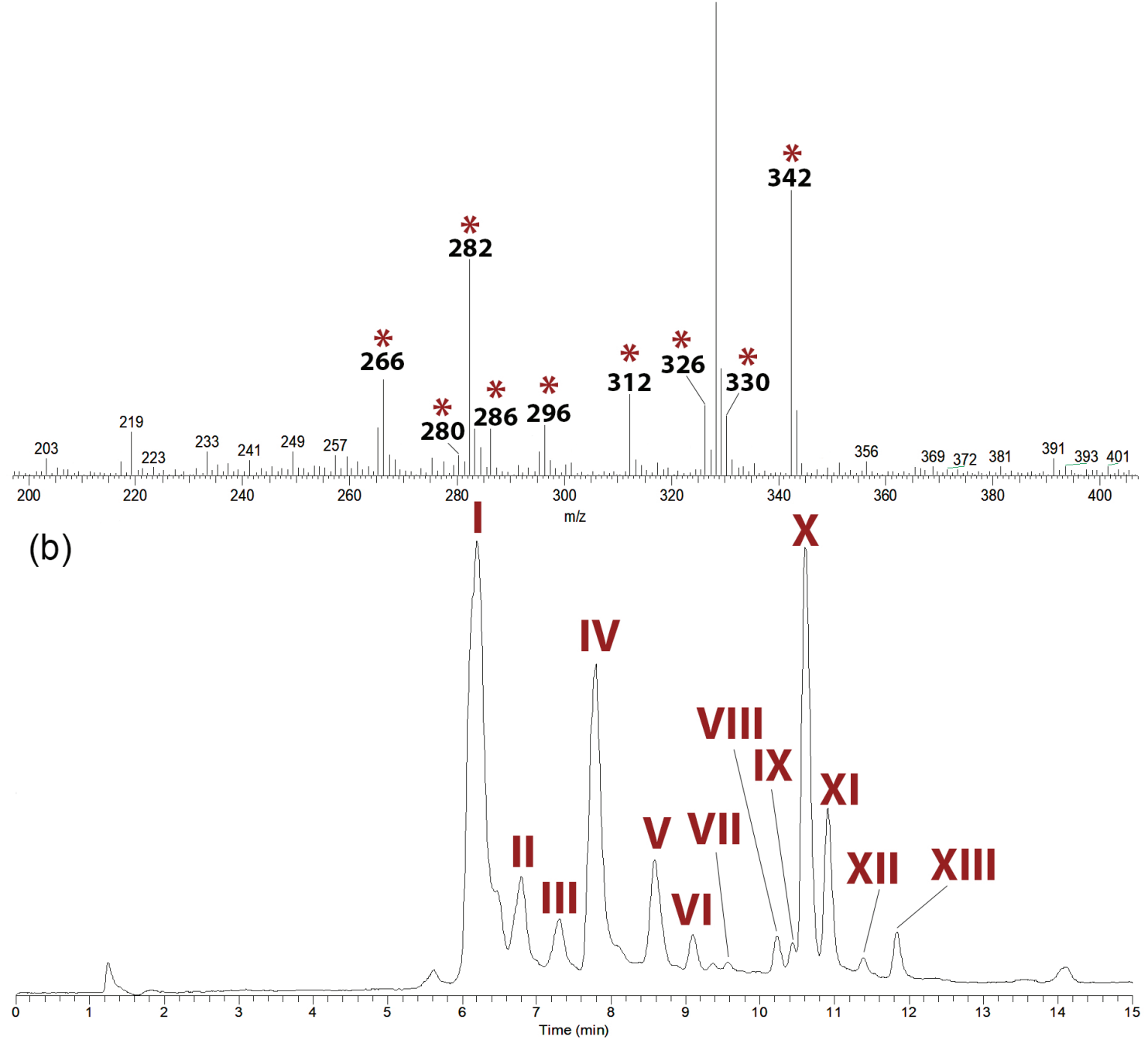

Figure 2. LS-MS alkaloid profile (a) from the leaf of $O$. amazonicum with * denoting the even $\mathrm{m} / \mathrm{z}$ of possible isoquinoline-derived alkaloid ions. HPLCMS total ion chromatogram (TIC) from crude alkaloid fraction (b).

species, ${ }^{4,5}$ the exact substitution pattern remained unknown, once for this skeleton different positions with the same substituents will provide the same fragmentation pattern. Similarly, base peak fragment ions at $\mathrm{m} / \mathrm{z} 192$ (precursor $\mathrm{m} / z$ 330; Figure S9, SI section) and 107 (precursor $m / z$ 286; Figure S4, SI section) have been previously associated with benzylisoquinoline skeletons with and without an $N$-methyl group, respectively (Figure $3 b$ ). The presence or absence of this group in benzylisoquinoline skeletons directly influences the fragmentation pathway. The ion at $\mathrm{m} / \mathrm{z} 192$ agrees with the presence of a methoxyl and hydroxyl groups at A ring, while the ion at $m / z 107$ agrees with a hydroxyl group at $\mathrm{C}$ ring. On the other hand, the loss of $138 \mathrm{Da}$ (precursor $\mathrm{m} / \mathrm{z}$ 330; Figure S9, SI section) and $179 \mathrm{Da}$ (precursor $m / z$ 286; Figure S4, SI section) suggest the presence of a methoxyl and hydroxyl groups at $\mathrm{C}$ and $\mathrm{A}$ ring, respectively. To reinforce this idea, other diagnostic product ions were observed, where $m / z 299$, 175, 143, and 137, from $m / z$ 330, and $m / z, 269$ and 143, from $\mathrm{m} / \mathrm{z}, 286$, were consistent with the benzylisoquinoline alkaloids reticuline (1) and norjuziphine (2), respectively, (Figure 4). ${ }^{5,19}$

The $\mathrm{MS}^{2}$ spectra of the protonated molecules at $\mathrm{m} / \mathrm{z} 282$, 296, 312 and $m / z 326$ presented pathways consistent with aporphine alkaloids with adjacent methoxyl groups at the A ring, and with presence or absence of $\mathrm{N}$-methyl groups. ${ }^{5,20}$ Consistently, their losses were assigned $17 \mathrm{Da}\left(-\mathrm{NH}_{3}\right)$ $(\mathrm{m} / z 282 \rightarrow 265$; Figure S3, SI section, and $m / z 312 \rightarrow 295$; Figure S6, SI section) or $31 \mathrm{Da}\left(-\mathrm{NH}_{2} \mathrm{CH}_{3}\right)(\mathrm{m} / z 296 \rightarrow 265$; Figure S5, SI section and $m / z \quad 326 \rightarrow 295$; Figure S7, SI section), followed by competitive losses of $15 \mathrm{Da}\left(-\mathrm{CH}_{3}\right)$ $(\mathrm{m} / z$ 265 $\rightarrow$ 250; Figure S3, SI section, and $m / z, 295 \rightarrow 280$; Figure S6, SI section) and $31 \mathrm{Da}\left(-\mathrm{OCH}_{3}\right)(\mathrm{m} / z, 265 \rightarrow 234$; Figure S5, SI section, and $m / z 295 \rightarrow 264$; Figure S7, SI 
(a) Tetrahydroprotoberberines

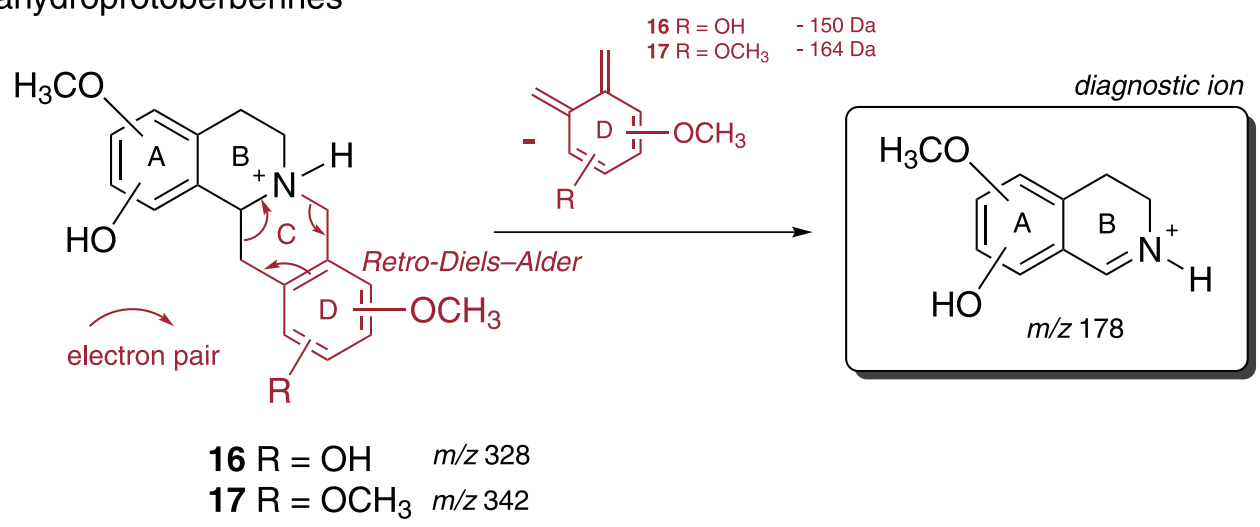

(b) Benzylisoquinolines

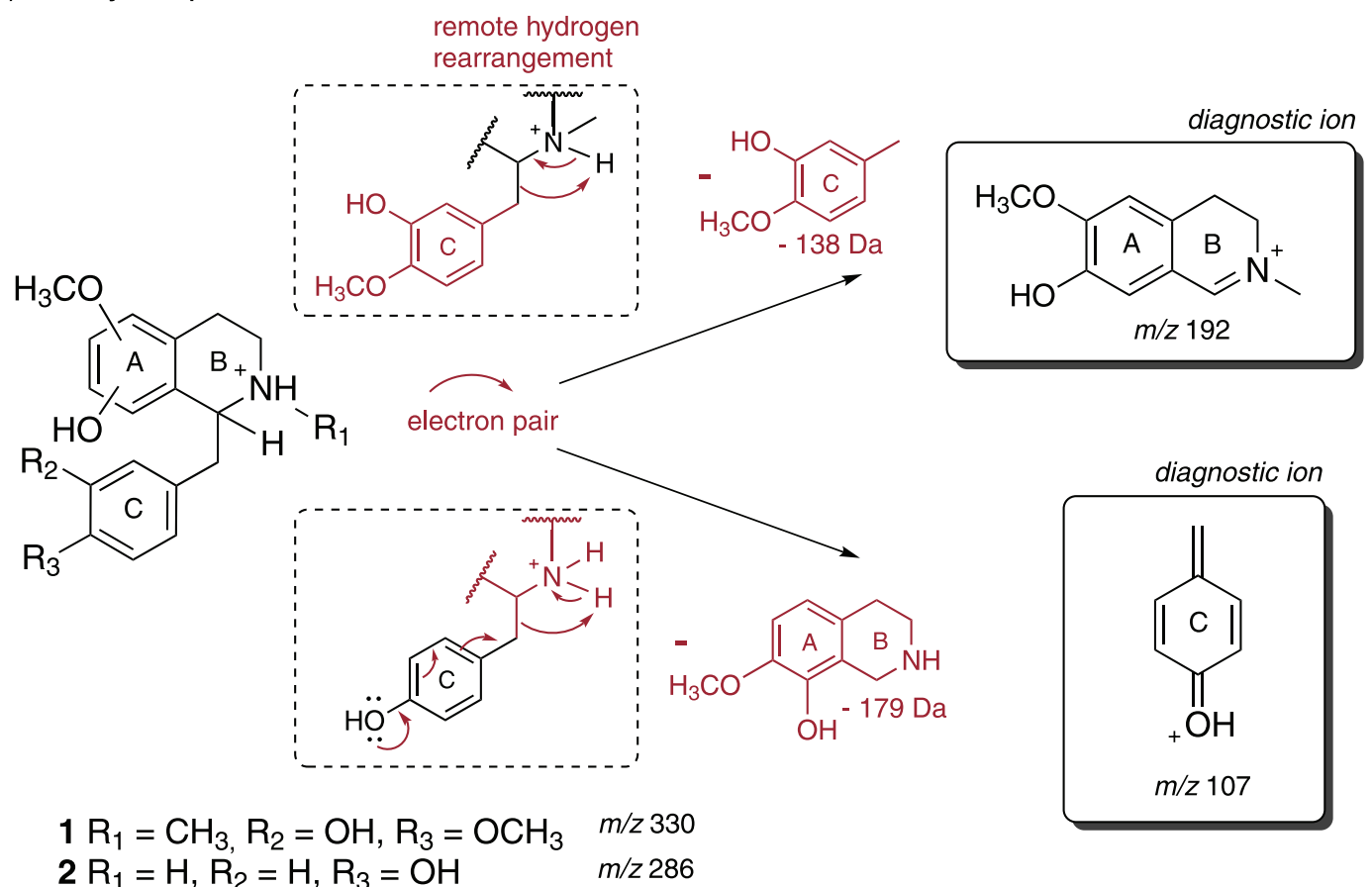

Figure 3. Proposed fragmentation pathways for the major product ions observed in LS-MS/MS spectra of tetrahydroprotoberberine ( $m / z$ 328 and 342 ) (a) and benzylisoquinoline $(\mathrm{m} / \mathrm{z}, 286$ and 330) (b) alkaloids.

section), confirming the two adjacent methoxyl groups (Figure 5). Therefore, the fragmentation patterns observed for the protonated molecules at $\mathrm{m} / \mathrm{z} 282$ and 312 were consistent with the aporphine alkaloids nornuciferine (3) and $O$-methylisopiline (4), ${ }^{5,21}$ respectively, and $\mathrm{m} / z 296$ and 326 were as their $N$-methyl forms, nuciferine (5) and $\mathrm{N}$-methyl- $\mathrm{O}$-methylisopiline (6).

In addition, $\mathrm{MS}^{2}$ spectra of the protonated molecules at $\mathrm{m} / \mathrm{z} 266$ and 280 presented strong evidence of the aporphine skeletons containing a methylenedioxy group with absence and presence of $N$-methyl group, respectively. An initial loss of $17 \mathrm{Da}\left(-\mathrm{NH}_{3}\right)(\mathrm{m} / z 266 \rightarrow 249$; Figure S1, SI section) or $31 \mathrm{Da}\left(-\mathrm{NH}_{2} \mathrm{CH}_{3}\right)(\mathrm{m} / z, 280 \rightarrow 249$; Figure $\mathrm{S} 2$, SI section), followed by subsequent losses of $30 \mathrm{Da}\left(\mathrm{CH}_{2} \mathrm{O}\right)$ $(\mathrm{m} / z 249 \rightarrow 219$; Figures $\mathrm{S} 1$ and S2, SI section) and $28 \mathrm{Da}$ $(-\mathrm{CO})(\mathrm{m} / z 219 \rightarrow 191$; Figures S1 and S2, SI section), observed in both spectra, reinforced the structural proposal (Figure 6). Therefore, the observed fragmentation patterns are consistent with the aporphine alkaloids anonaine (7) and its $N$-methyl form, $N$-methylanonaine (8), respectively. Thus, the initial profile by the positive LS-MS allowed the tentative identification of 8 isoquinoline-derived alkaloids, with tetrahydroprotoberberines and aporphine as the major compounds. However, it should be noted that the recognition of isobaric and minor compounds from direct MS analysis can have been compromised by matrix effect, ${ }^{22}$ being required HPLC-DAD-MS analysis for a more comprehensive investigation. 

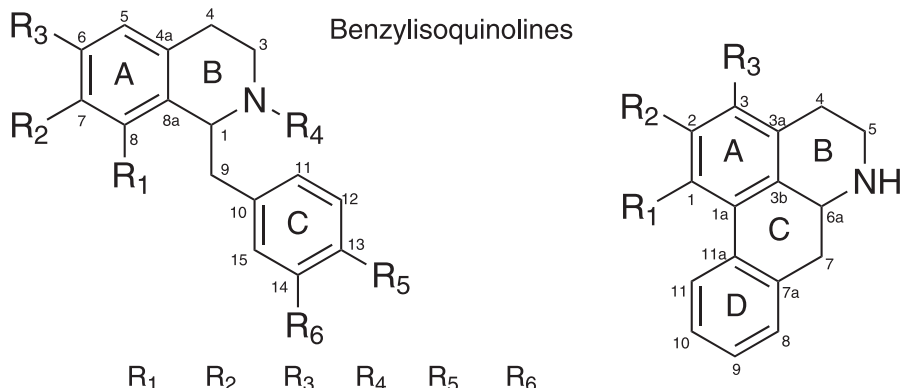

Aphorphines
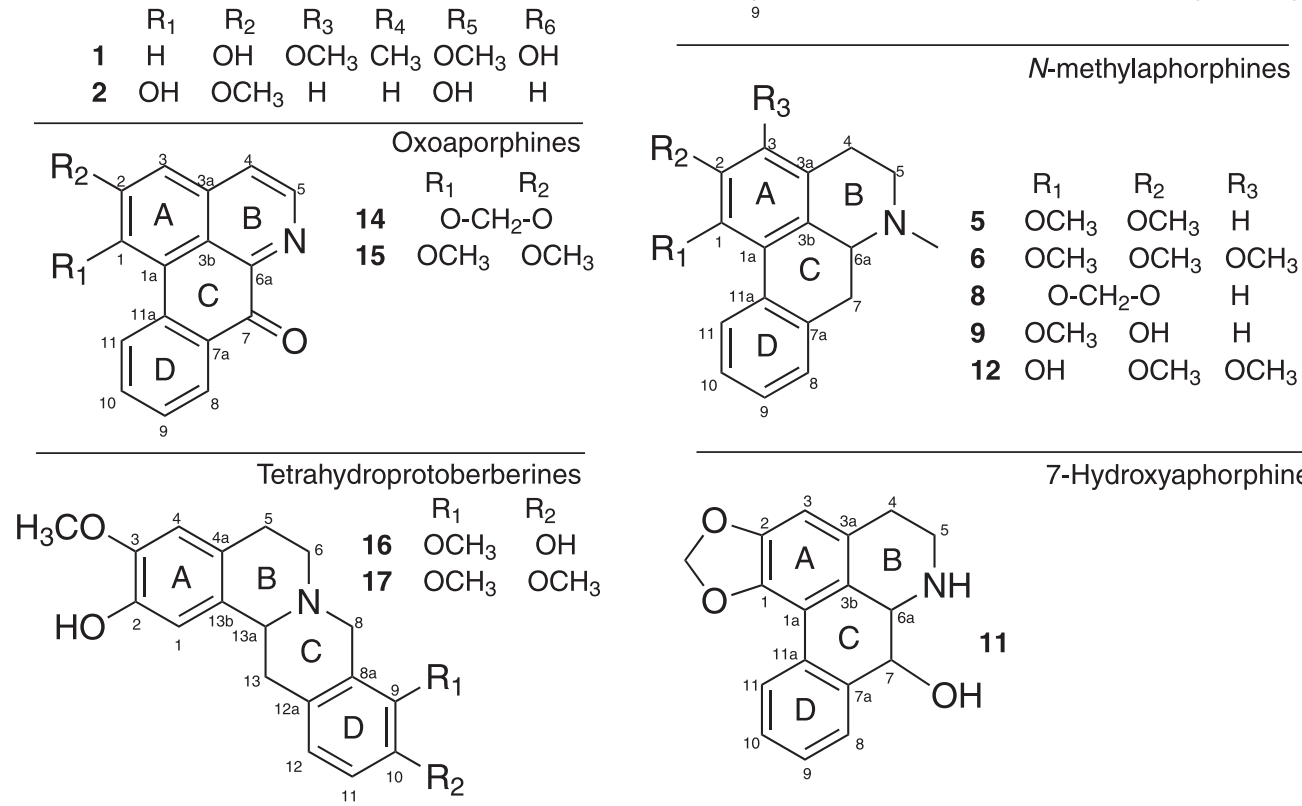

7-Hydroxyaphorphine

Figure 4. Tentatively identified isoquinoline-derived alkaloids from the leaves of $O$. amazonicum.
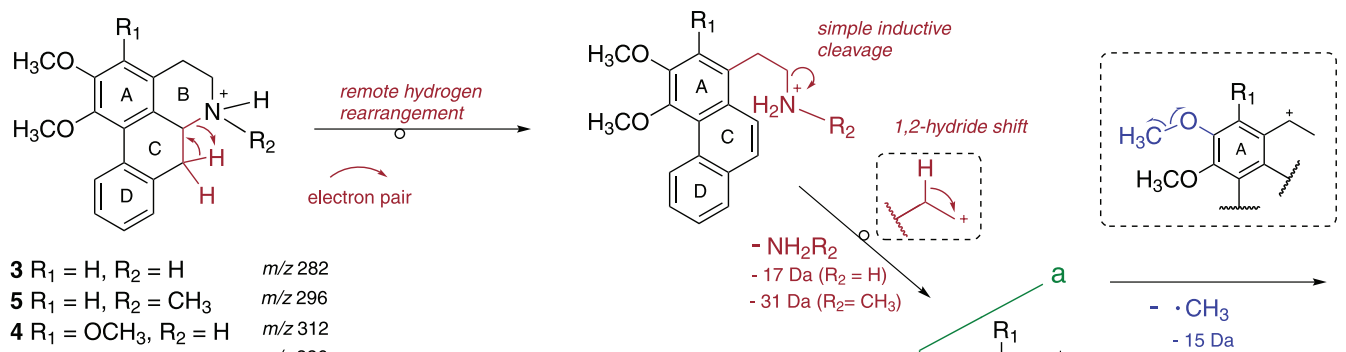

$\begin{array}{ll}3 \mathrm{R}_{1}=\mathrm{H}, \mathrm{R}_{2}=\mathrm{H} & m / z 282 \\ \mathbf{5} \mathrm{R}_{1}=\mathrm{H}, \mathrm{R}_{2}=\mathrm{CH}_{3} & m / z 296\end{array}$ $\begin{array}{ll}5 \mathrm{R}_{1}=\mathrm{H}, \mathrm{R}_{2}=\mathrm{CH}_{3} & \mathrm{~m} / \mathrm{z} 296 \\ 4 \mathrm{R}_{1}=\mathrm{OCH}_{3}, \mathrm{R}_{2}=\mathrm{H} & \mathrm{m} / \mathrm{z} 312\end{array}$ $6 \mathrm{R}_{1}=\mathrm{OCH}_{3}, \mathrm{R}_{2}=\mathrm{CH}_{3} \mathrm{~m} / \mathrm{z} 326$
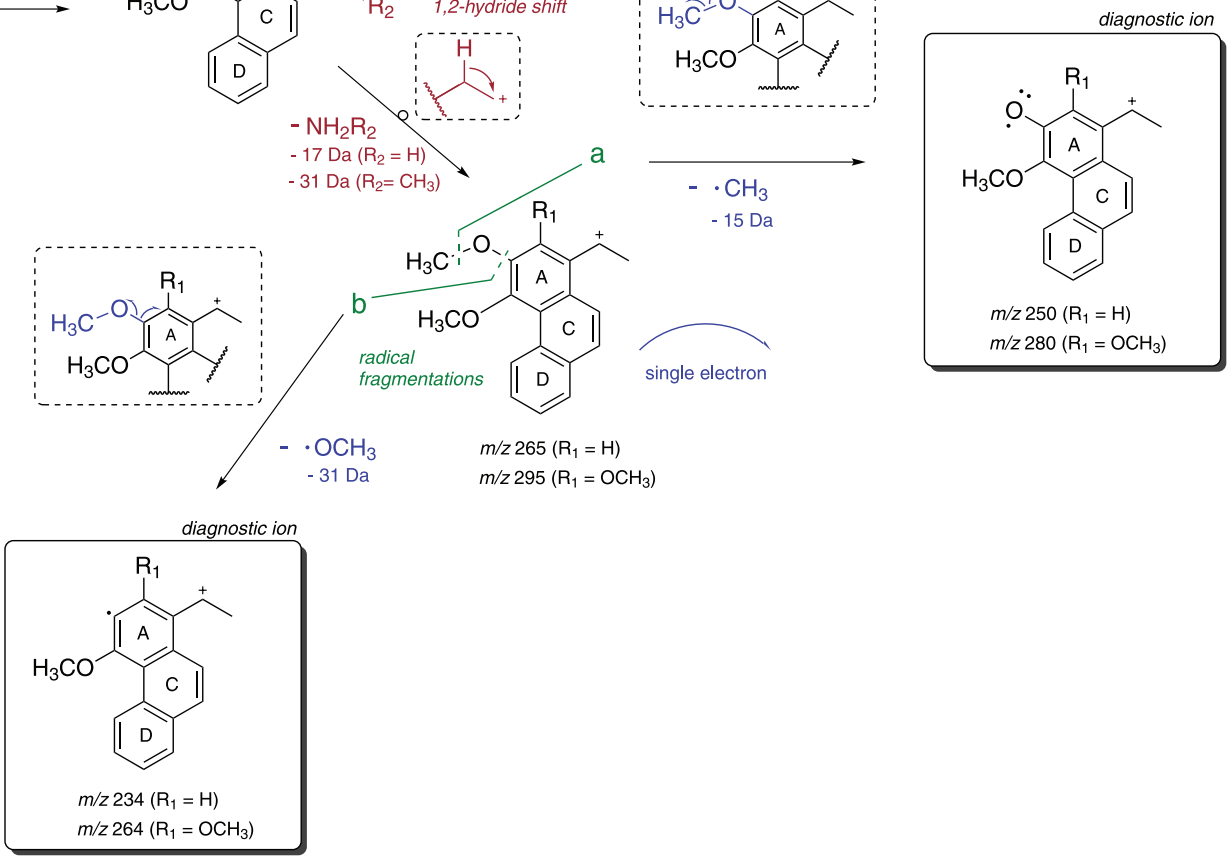

Figure 5. Proposed fragmentation pathways for the major product ions observed in LS-MS/MS spectra of aporphine alkaloids with adjacent methoxyl groups at ring A $(\mathrm{m} / \mathrm{z}, 282,296,312$ and 326$)$. 
(a) Aporphine bearing adjacent hydroxyl and methoxyl at ring $A$
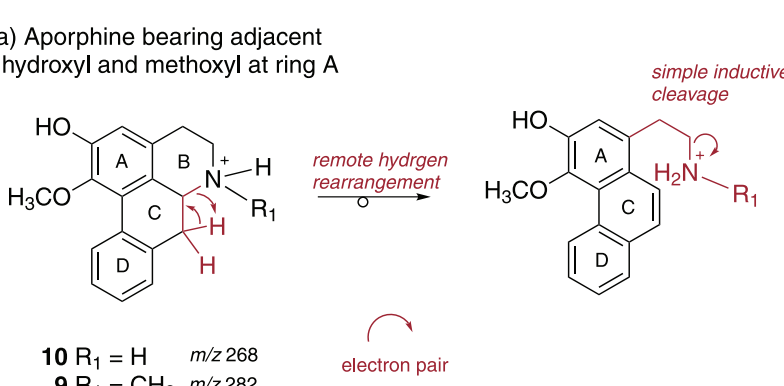

$$
\begin{array}{rlr}
10 \mathrm{R}_{1} & =\mathrm{H} & m / z 268 \\
9 \mathrm{R}_{1} & =\mathrm{CH}_{3} & m / z 282
\end{array}
$$
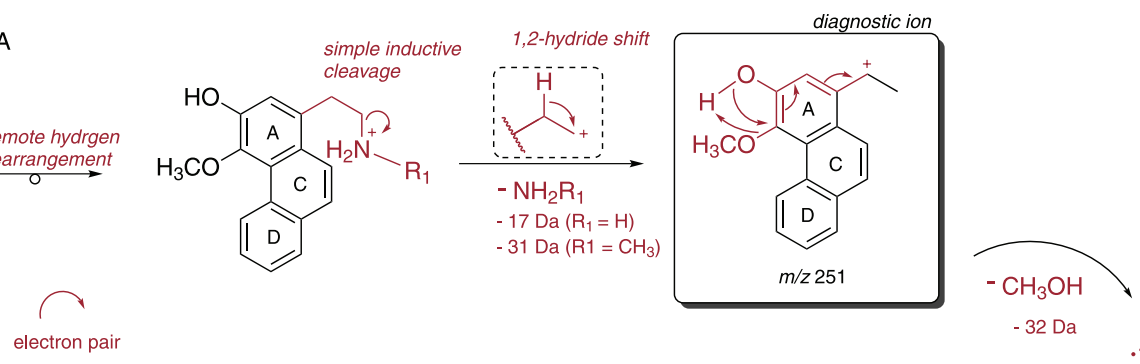

(b) Aporphine bearing a methylenedioxy bridge at ring $A$

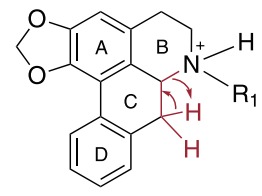

remote hydrgen $\underset{\mathrm{r}}{\stackrel{\mathrm{O}}{\longrightarrow}}$

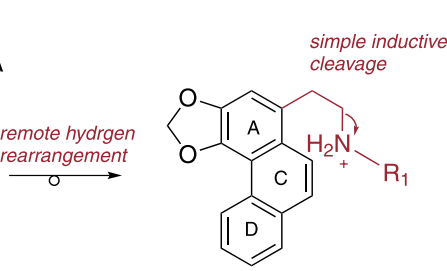

$7 \mathrm{R}_{1}=\mathrm{H} \quad \mathrm{m} / \mathrm{z} 266$ $8 \mathrm{R}_{1}=\mathrm{CH}_{3} \quad \mathrm{~m} / \mathrm{z} 280$
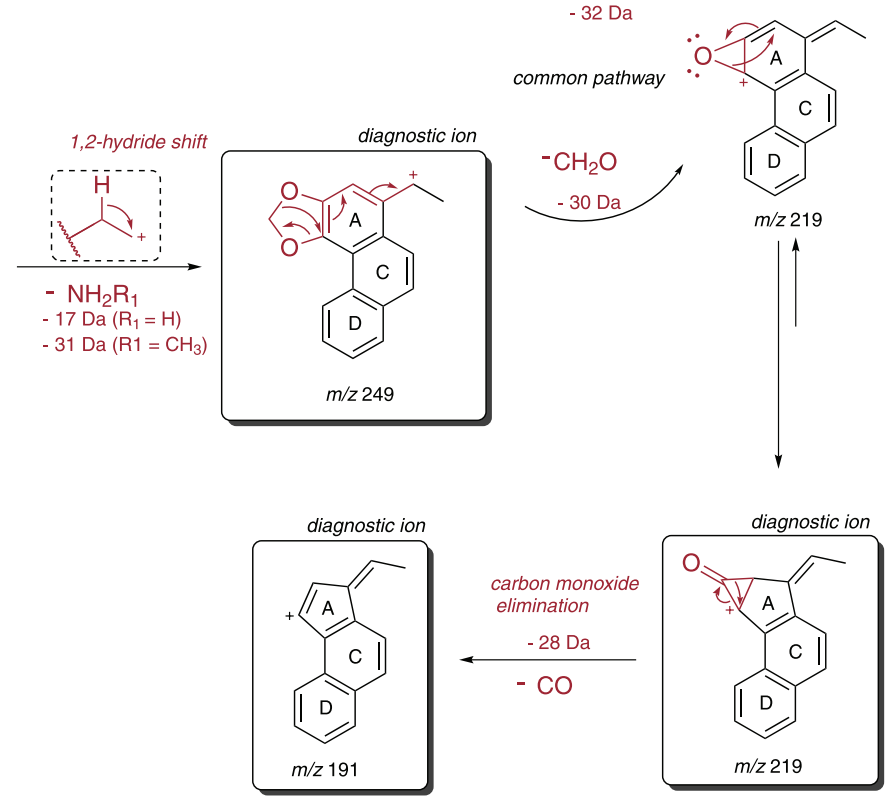

Figure 6. Proposed fragmentation pathways for the major product ions observed in LS-MS/MS and HPLC-MS/MS spectra of aporphine alkaloids with adjacent hydroxyl and methoxyl groups at ring A ( $\mathrm{m} / \mathrm{z}, 268$ and 282) (a) and methylenedioxi bridge at ring A ( $\mathrm{m} / \mathrm{z}, 266$ and 280$)(\mathrm{b})$.

\section{HPLC-DAD-MS/MS analysis}

The HPLC-MS total ion chromatogram (TIC) of the crude alkaloid fraction (Figure $2 \mathrm{~b}$ ) corroborated with the LS-MS data. Thereby, the most intense ions of the LS-MS experiment, tetrahydroprotoberberine alkaloids at $m / z, 328$ and 342 were the main peaks I (retention time $\left(\mathrm{t}_{\mathrm{R}}\right) 6.19 \mathrm{~min}$ ) and IV $\left(\mathrm{t}_{\mathrm{R}} 7.80 \mathrm{~min}\right)$ at the HPLC-MS analysis (Table 1), respectively. The protonated non- $N$-methylated aporphine alkaloids at $\mathrm{m} / \mathrm{z}, 282,266$ and 312 were observed at the peaks $\mathrm{X}, \mathrm{XI}$ and XIII $\left(\mathrm{t}_{\mathrm{R}} 10.61,10.91\right.$ and $11.84 \mathrm{~min}$, respectively), while their $N$-methyl homologs at $\mathrm{m} / z 296$, 280 and 326 were observed at the peaks VIII, IX and XII $\left(\mathrm{t}_{\mathrm{R}} 10.23,10.43\right.$ and $11.38 \mathrm{~min}$, respectively), suggesting that $N$-methyl aporphine alkaloids present lower retention in $\mathrm{C}-18$ column compared to their non- $N$-methylated homologues. Benzylisoquinolines were also observed at the TIC, where $\mathrm{m} / \mathrm{z} 330$ (peak II, $\mathrm{t}_{\mathrm{R}} 6.79 \mathrm{~min}$ ) and 286 (peak V, $t_{R} 8.59 \mathrm{~min}$ ) presented chromatographic behavior similar to tetrahydroprotoberberines.

The HPLC-MS analysis also displayed the presence of minor isobaric alkaloids related to values recorded by LS-MS at $\mathrm{m} / z 342$ (peak III, $\mathrm{t}_{\mathrm{R}} 7.30 \mathrm{~min}$ ), 282 (peaks V,
8.59 min and VII, $t_{R} 9.56 \mathrm{~min}$ ), and 312 (peak IX). $\mathrm{MS}^{2}$ spectrum of the $m / z, 342$ ion (peak III) recorded fragments at $\mathrm{m} / \mathrm{z} 192$ (base peak) and 165 (Figure S34, SI section), suggesting a benzylisoquinoline derivative. $\mathrm{MS}^{2}$ spectrum of the $\mathrm{m} / \mathrm{z}, 282$ ion (peak V), suggested the presence of an $N$-methyl aporphine structure with vicinal hydroxyl and methoxyl groups. The initial loss of $31 \mathrm{Da}\left(-\mathrm{NH}_{2} \mathrm{CH}_{3}\right)$ $(\mathrm{m} / \mathrm{z} 282 \rightarrow 251)$, followed by subsequent losses of $32 \mathrm{Da}\left(-\mathrm{CH}_{3} \mathrm{OH}\right)(\mathrm{m} / \mathrm{z}, 251 \rightarrow 219)$ and $28 \mathrm{Da}(-\mathrm{CO})(\mathrm{m} / \mathrm{z}$ $219 \rightarrow 191$ ) (Figure S37, SI section) reinforced this proposal (Figure 6). This fragmentation pattern was consistent with the compound $N$-methylasimilobine (9), the $N$-methylated form of asimilobine (10), which was observed at peak VI $\left(\mathrm{m} / \mathrm{z}, 268, \mathrm{t}_{\mathrm{R}} 9.10 \mathrm{~min}\right)$. The latter was also confirmed by its fragmentation pattern $(\mathrm{m} / z 268 \rightarrow 251 \rightarrow 219 \rightarrow 191$; Figure S38, SI section), which is in agreement with previous data. ${ }^{4,5}$ The third isobaric alkaloid at $\mathrm{m} / \mathrm{z} 282$ (peak VII) presented in its $\mathrm{MS}^{2}$ spectrum an initial loss of $18 \mathrm{Da}\left(-\mathrm{H}_{2} \mathrm{O}\right)(\mathrm{m} / z 282 \rightarrow 264)$, followed by subsequent losses of $30 \mathrm{Da}\left(-\mathrm{CH}_{2} \mathrm{O}\right)(\mathrm{m} / \mathrm{z} 264 \rightarrow 234)$ and $28 \mathrm{Da}(-\mathrm{CO})$ $(\mathrm{m} / \mathrm{z} 234 \rightarrow 206)$ (Figure S39, SI section). This uncommon fragmentation is in coherence to the aporphine alkaloid norushinsunine (11), a 7-hydroxyaporphine derivative 
Table 1. Isoquinoline-derived alkaloids in O. amazonicum tentatively identified by HPLC-DAD-MS/MS and NMR analyses

\begin{tabular}{|c|c|c|c|c|c|c|}
\hline Peak & Compound & $\mathrm{t}_{\mathrm{R}}{ }^{\mathrm{a} / \min }$ & Class $^{\mathrm{b}}$ & {$[\mathrm{M}+\mathrm{H}]^{+}$} & $\mathrm{MS} / \mathrm{MS}^{\mathrm{c}}$ & $\lambda_{\max }{ }^{\mathrm{d}} / \mathrm{nm}$ \\
\hline I & stepholidine (16) & 6.19 & $\mathrm{~T}$ & 328 & $178^{*}, 151$ & 227,283 \\
\hline II & reticuline (1) & 6.79 & $\mathrm{~B}$ & 330 & $\begin{array}{c}299,192 *, 175 \\
143,137\end{array}$ & \\
\hline III & unknown & 7.30 & B & 342 & $192 *, 165$ & \\
\hline IV & isocorypalmine (17) & 7.80 & $\mathrm{~T}$ & 342 & $178^{*}, 165,151$ & 232,282 \\
\hline \multirow[t]{2}{*}{ V } & norjuziphine (2) & 8.59 & B & 286 & $\begin{array}{c}269,237,143 \\
107^{*}\end{array}$ & \\
\hline & $N$-methylasimilobine $(\mathbf{9})$ & & A & 282 & $251,219,191^{*}$ & \\
\hline VI & asimilobine (10) & 9.10 & A & 268 & $251,219,191^{*}$ & \\
\hline \multirow[t]{2}{*}{ VII } & norushinsunine (11) & 9.56 & A & 282 & $264,234,206^{*}$ & \\
\hline & liriodenine (14) & & $\mathrm{O}$ & 276 & $248^{*}, 220$ & \\
\hline VIII & nuciferine (5) & 10.23 & A & 296 & $265,250,234 *$ & $218,233,270$ \\
\hline \multirow[t]{2}{*}{ IX } & $N$-methylanonaine (8) & 10.43 & A & 280 & $249 *, 219,191$ & $239,271,312$ \\
\hline & $N$-methylisopiline (12) & & A & 312 & $281,266,250^{*}$ & \\
\hline $\mathrm{X}$ & nornuciferine (3) & 10.61 & A & 282 & $265,250,234^{*}$ & $219,233,270$ \\
\hline \multirow[t]{2}{*}{ XI } & anonaine (7) & 10.91 & A & 266 & $249 *, 219,191$ & $245,271,315$ \\
\hline & isopiline (13) & & A & 298 & $281,266,250 *$ & \\
\hline XII & $\mathrm{N}$-methyl-O-methylisopiline (6) & 11.38 & A & 326 & $295,280^{*}, 264$ & $222,231,275$ \\
\hline \multirow[t]{2}{*}{ XIII } & $O$-methylisopiline (4) & 11.84 & A & 312 & $295,280^{*}, 264$ & $223,232,275$ \\
\hline & lysicamine (15) & & $\mathrm{O}$ & 292 & $277 *, 248$ & \\
\hline
\end{tabular}

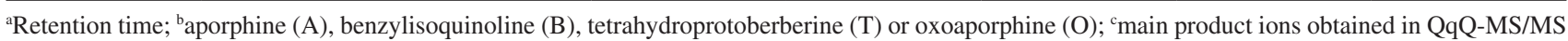
analyses with $*$ denoting the base peak; ${ }^{\mathrm{d}} \lambda_{\max }$ between $200-400 \mathrm{~nm}$.

containing a methylenedioxy group, whose loss of water and a subsequent 1,2-hydride shift resulting in a more stable fragment ion (Figure 7). This observation suggests that a substitution at C-7 in aporphine skeletons has substantial influence over the first loss, but not the subsequent. The confirmation of this substance was performed through comparison of the $\mathrm{MS}^{2}$ spectrum with standard previously isolated and identified by the authors. ${ }^{21}$

The fourth minor isobaric at $\mathrm{m} / \mathrm{z} 312$ (peak IX) presented $\mathrm{MS}^{2}$ fragmentation consistent with an $\mathrm{N}$-methyl aporphine derivative with adjacent methoxyl groups $(\mathrm{m} / \mathrm{z} 312 \rightarrow 281 \rightarrow 266 \rightarrow 250$; Figure S43, SI section), which is compatible with the alkaloid $N$-methylisopiline (12). Its non- $N$-methylated homolog was observed at $m / z 298$ (peak $\mathrm{XI})(\mathrm{m} / z 298 \rightarrow 281 \rightarrow 266 \rightarrow 250$; Figure S46, SI section) and attributed to the aporphine alkaloid isopiline (13). The confirmation of this proposal was performed through comparison of the $\mathrm{MS}^{2}$ spectrum with a standard previously isolated and identified by the authors. ${ }^{20}$ Additionally, two protonated oxoaporphine alkaloids observed at $\mathrm{m} / \mathrm{z}, 276$ (peak VII) and 292 (peak XIII) were tentatively identified as liriodenine (14) and lysicamine (15), respectively, through comparison of their $\mathrm{MS}^{2}$ spectra with those reported in the literature. ${ }^{8}$
To reinforce the tentative identification of the proposed isoquinoline-derived alkaloids, the DAD spectrum of the main chromatographic peaks were compared among themselves. Initially, it was observed the strong spectral similarity between the tetrahydroprotoberberine alkaloids present at the peaks I and IV (Figure 8a), pointing to the same substitution pattern, which reinforces that the protonated alkaloid at $\mathrm{m} / \mathrm{z} 342$ (peak IV) is a methylation product of the alkaloid at $m / z 328$ (peak I), as evidenced by $\mathrm{MS}^{2}$ analysis. Similar behavior was also observed for the aporphine derivatives, where the peaks VIII and X, IX and XI, and XII and XIII shared similar UV spectra (Figures S26-S31, SI section). Discreet difference between the peaks IX and XI may be due to the co-elution effect of $\mathrm{N}$-methylanonaine and $\mathrm{N}$-methylisopiline in peak IX, and anonaine and isopiline in peak XI (Figure 8b). The absence of significant hypsochromic or bathochromic shifts for the other peaks agrees with the inclusion of a methyl group at the heterocyclic nitrogen. Since aporphine and noraporphine alkaloids present invariably substitution at positions 1 and 2, with prominent peaks at 270-280 $\mathrm{nm}$ and a shoulder or a smaller peak at $310-320 \mathrm{~nm}$ in UV spectra when positions 10 and 11 are unsubstituted, ${ }^{23}$ it is plausible the $\mathrm{C}-3$ substitution proposals by $\mathrm{MS}^{2}$ for the aporphine 

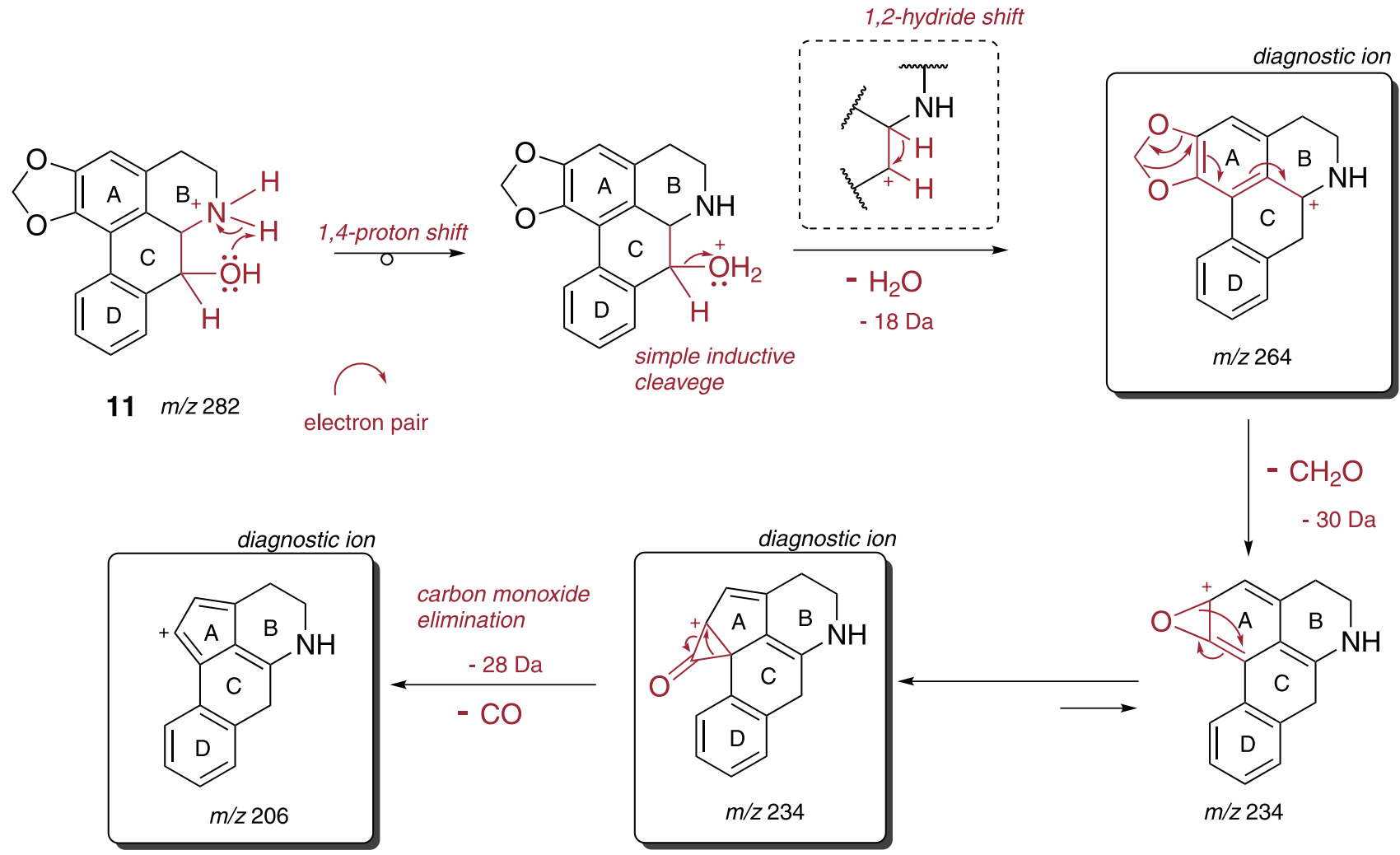

Figure 7. Proposed fragmentation pathway for the main product ions observed in HPLC-MS/MS spectra of 7-hydroxyaporphine alkaloid at $m / z 282$.

alkaloids $N$-methylisopiline (12), isopiline (13), $N$-methyl$O$-methylisopiline (6), and $O$-methylisopiline (4). Thus, the HPLC-DAD-MS/MS analysis allowed additionally to LS-MS the tentative identification of seven isoquinolinederived alkaloids, besides to access additional information such as chromatographic behavior of analogous alkaloids and the UV spectra profile, providing a more comprehensive investigation of the O. amazonicum leaf alkaloid content. At this point, the exact substitution pattern of the major tetrahydroprotoberberine alkaloids present at peaks I and IV remained unknown, being the crude alkaloid fraction subjected to 1D and 2D NMR analysis for the unequivocal assignment of the major compounds.

\section{Tetrahydroprotoberberine 1D and 2D NMR analysis}

Ratifying the LS-MS analysis, in which the main alkaloids in the leaf sample were from the tetrahydroprotoberberine class $(\mathrm{m} / \mathrm{z}, 328$ and 342$)$, the ${ }^{1} \mathrm{H}$ NMR spectrum of the total alkaloid fraction exhibited as the major signals typical doublet signals at $\delta_{\mathrm{H}} 6.79(\mathrm{~d}, J 8.5 \mathrm{~Hz})$ and $6.73(\mathrm{~d}$, $J 8.5 \mathrm{~Hz}$ ), an indicative of an ortho-substituted system, as well singlet signals at $\delta_{\mathrm{H}} 6.75(\mathrm{~s})$ and $6.67(\mathrm{~s})$, characteristic of para-substituted tetrahydroprotoberberine alkaloids, and two methoxyl signals at $\delta_{\mathrm{H}} 3.82(\mathrm{~s})$ and $\delta_{\mathrm{H}} 3.80(\mathrm{~s})$. Correlations of these signals with the carbons at $\delta_{\mathrm{C}} 125.2$,
$116.3,112.3,112.9,56.3$ and 60.2 , respectively, were observed in the heteronuclear single quantum coherence (HSQC) map. The confirmation of the ortho pattern at D ring was reached through the heteronuclear multiple bond correlation (HMBC) experiment. In this, $J^{3}$-couplings for the proton at $\delta_{\mathrm{H}} 6.79(\mathrm{H}-12)$ with carbons at $\delta_{\mathrm{C}} 36.2$ (C-13), $128.3(\mathrm{C}-8 \mathrm{a})$, and 148.7 (C-10), and for the proton at $\delta_{\mathrm{H}} 6.73(\mathrm{H}-11)$ with carbons at $\delta_{\mathrm{C}} 126.7(\mathrm{C}-12 \mathrm{a})$ and 144.8 (C-9) evidenced our proposal. This was reinforced by the $J^{3}$-coupling between the methoxyl protons at $\delta_{\mathrm{H}} 3.80$ (s) and the C-9 carbon. Thus, the structure of the main tetrahydroprotoberberine alkaloid was established as stepholidine (16) and supported by comparison of the NMR data with those existing in the literature. ${ }^{24}$ This proposal is in accordance with the molecular formula $\mathrm{C}_{19} \mathrm{H}_{22} \mathrm{NO}_{4}$ $(\mathrm{m} / \mathrm{z}$ 328.1539, Figure S59, SI section), as determined by high-resolution electrospray ionization mass spectrometry (HR-ESI-MS). Likewise, another set of aromatic protons, analog to that observed to the stepholidine's ortho-substituted system, was observed at $\delta_{\mathrm{H}} 6.90(\mathrm{~d}$, $J 8.5 \mathrm{~Hz})$ and $6.84(\mathrm{~d}, J 8.5 \mathrm{~Hz})$. These data, along with $\mathrm{MS}^{2}$ analysis, allowed identifying the second main tetrahydroprotobererine alkaloid as isocorypalmine (17), which is consistent with the literature data. ${ }^{25}$ This proposal is also in accordance with the molecular formula $\mathrm{C}_{20} \mathrm{H}_{23} \mathrm{NO}_{4}$ $(\mathrm{m} / \mathrm{z}$ 342.1697, Figure S60, SI section), as determined 


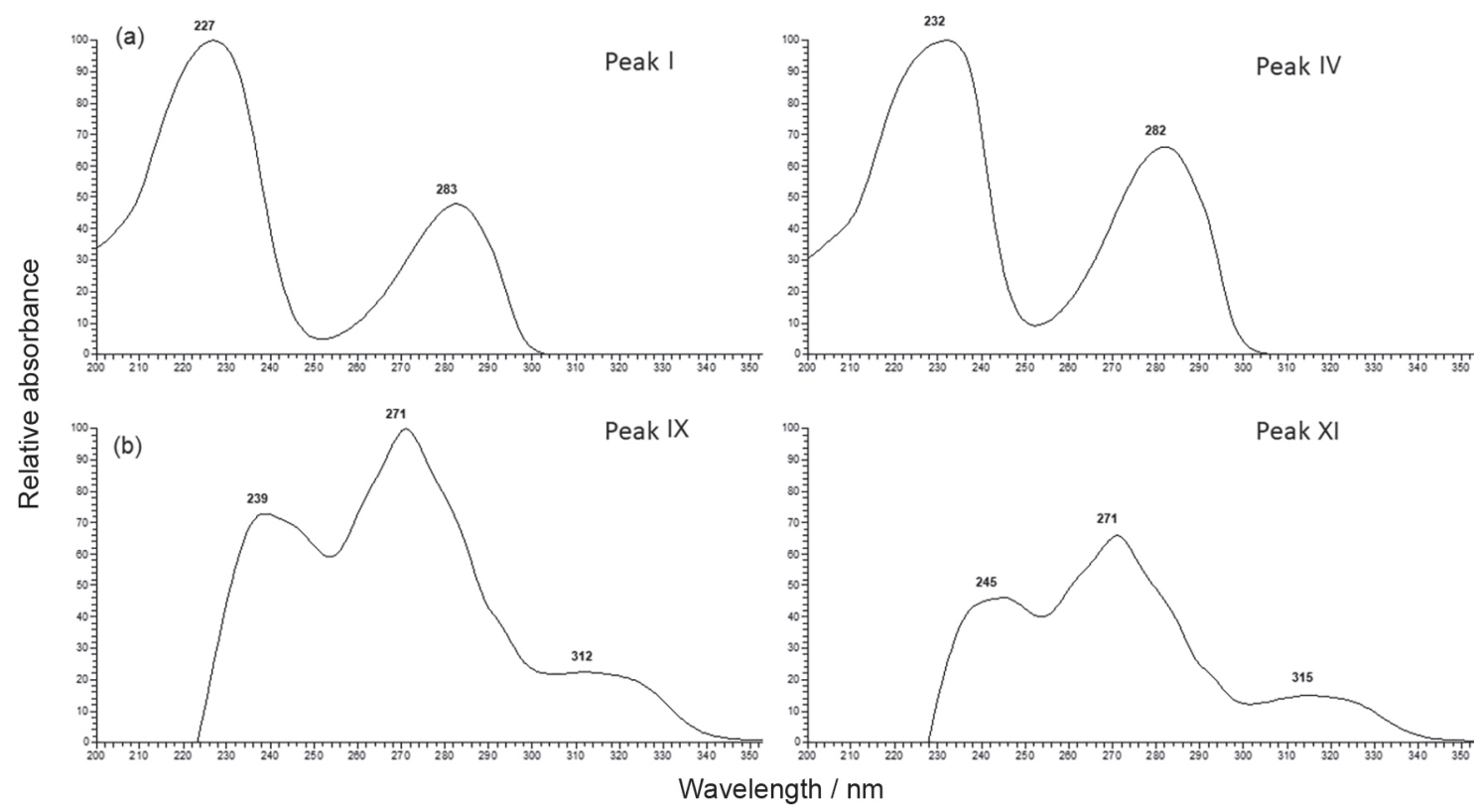

Figure 8. UV spectra arising from the HPLC peaks I and IV(a), and IX and XI (b).

by HR-ESI-MS. Several biological activities have been described for these major alkaloids, highlighting the stepholidine potential in the treatment of schizophrenia and Parkinson's disease ${ }^{26}$ and the potential of both alkaloids as an antipsychotic drug with dual behavior D1 agonist and D2 antagonist receptors. ${ }^{27,28}$

\section{Conclusions}

The integrative approach based on the alkaloid profile analysis by LS-MS, a rapid and low-cost sampling methods for direct analysis of complex mixtures, followed by a complementary and robust dereplication through HPLC-DAD-MS/MS and NMR analysis showed to be a useful strategy for dereplication of isoquinoline-derived alkaloids. Tetrahydroprotoberberine, aporphine and analogue alkaloids were highlighted as major compounds in the leaves of $O$. amazonicum, while benzylisoquinoline and oxoaporphine presented discrete distribution. Our findings in the phytochemical study of $O$. amazonicum reinforce the chemotaxonomic significance of isoquinolinederived alkaloids for Annonaceae family, particularly, to the Onychopetalum and close-related genera.

\section{Supplementary Information}

Supplementary information (Figures S1-S60 and Table S1) is available free of charge at http://jbcs.sbq.org.br as PDF file.

\section{Acknowledgments}

The authors are grateful to Prof Richard N. Zare and Prof Boniek Gontijo Vaz for their help with the homebuilt LS-MS interface, Central Analítica (UFAM) for MS and NMR analysis, and CAPES, CNPq, FINEP, FAPEAM and FAPESP (Proc. 2014/50244-6) for the financial support.

\section{References}

1. Maas, P. J. M.; Westra, L. Y. T.; Vermeer, M.; Blumea 2007, 52, 413.

2. Silva, F. M. A.; Lima, B. R.; Soares, E. R.; Almeida, R. A.; Silva-Filho, F. A.; Corrêa, W. R.; Salvador, M. J.; Souza, A. Q. L.; Koolen, H. H. F.; Souza, A. D. L.; Pinheiro, M. L. B.; Rev. Bras. Farmacogn. 2015, 25, 11.

3. Adams, M.; Gmunder, F.; Hamburger, M.; J. Ethnopharmacol. 2007, 113, 363.

4. Silva, F. M. A.; Silva-Filho, F. A.; Lima, B. R.; Almeida, R. A.; Soares, E. R.; Koolen, H. H. F.; Souza, A. D. L.; Pinheiro, M. L. B.; J. Braz. Chem. Soc. 2016, 27, 599.

5. Soares, E. R.; Silva, F. M. A.; Almeida, R. A.; Lima, B. R.; Silva-Filho, F. A.; Koolen, H. H. F.; Pinheiro, M. L. B.; Souza, A. D. L.; Phytochem. Anal. 2015, 26, 339.

6. Almeida, M. E. L.; Braz-Filho, R.; von Bülow, V.; Gottlieb, O. R.; Maia, J. G. S.; Phytochemistry 1976, 15, 1186.

7. Lima, B. R.; Silva, F. M. A.; Soares, E. R.; Almeida, R. A.; Silva-Filho, F. A.; Pereira-Junior, R. C.; Tasco, A. J. H.; Salvador, M. J.; Koolen, H. H. F.; Souza, A. D. L.; Pinheiro, M. L. B.; Nat. Prod. Res. 2016, 30, 2356. 
8. Silva, F. M. A.; Bataglion, G. A.; Almeida, R. A.; Heerdt, G.; Sousa, I. L.; Silva-Filho, F. A.; Alencar, D. C.; Costa, E. V.; Souza, A. D. L.; Pinheiro, M. L. B.; Morgon, N. H.; Koolen, H. H. F.; Int. J. Mass Spectrom. 2017, 418, 30.

9. Silva, F. M. A.; Silva-Filho, F. A.; Lima, B. R.; Almeida, R. A.; Mendonça, D. M.; Pereira-Junior, R. C.; Dutra, L. M.; Barison, A.; Koolen, H. H. F.; Souza, A. D. L.; Pinheiro, M. L. B.; Helv. Chim. Acta 2016, 99, 494.

10. Liu, J.; Wang, H.; Cooks, R. G.; Ouyang, Z.; Anal. Chem. 2011, 83, 7608 .

11. Monge, M. E.; Harris, G. A.; Dwivedi, P.; Fernández, F. M.; Chem. Rev. 2013, 113, 2269.

12. Politi, M.; Chávez, M. I.; Cañada, F. J.; Jiménez-Barbero, J.; Eur. J. Org. Chem. 2005, 7, 1392.

13. Chauthe, S. K.; Sharma, R. J.; Aqil, F.; Gupta, R. C.; Singh, I. P.; Phytochem. Anal. 2012, 23, 689.

14. Bringmann, G.; Wohlfarth, M.; Rischer, H.; Schlauer, J.; Brun, R.; Phytochemistry 2002, 61, 195.

15. Karioti, A.; Giocaliere, E.; Guccione, C.; Pieraccini, G.; Gallo, E.; Vannacci, A.; Bilia, A. R.; J. Pharm. Biomed. Anal. 2014, $88,7$.

16. Ribeiro, J. E. L. S.; Hopkins, M. J. G.; Vicentini, A.; Sothers, C. A.; Costa, M. A. S.; Brito, J. M.; Souza, M. A. D.; Martins, L. H. P.; Lohmann, L. G.; Assunção, P. A. C. L.; Pereira, E. C.; Silva, C. F.; Mesquita, M. R.; Procópio, L. C.; Flora da Reserva Ducke: Guia de Identificação das Plantas Vasculares de uma Floresta de Terra Firme na Amazônia Central, INPA: Manaus, Brasil, 1999.
17. Sneha, M.; Dualy, M. T.; Zare, R. N.; Int. J. Mass Spectrom. 2017, 418, 156.

18. Demarque, D. P.; Crotti, A. E.; Vessecchi, R.; Lopes, J. L.; Lopes, N. P.; Nat. Prod. Rep. 2016, 33, 432.

19. Shangguan, Y.; He, J.; Kang, Y.; Wang, Y.; Yang, P.; Guo, J.; Huang, J.; Phytochem. Anal. 2018, 29, 101.

20. Stévigny, C.; Jiwan, J. L. H.; Rozenberg, R.; Hoffmann, E.; Leclercq, J. Q.; Rapid Commun. Mass Spectrom. 2004, 18, 523.

21. Silva, F. M. A.; Silva-Filho, F. A.; Souza, C. A. S.; Maciel, J. B.; Costa, E. V.; Barison, A.; Koolen, H. H. F.; Souza, A. D. L.; Pinheiro, M. L. B.; Biochem. Syst. Ecol. 2018, 79, 12.

22. Lin, L.; Yu, Q.; Yan, X.; Hang, W.; Zheng, J.; Xing, J.; Huang, B.; Analyst 2010, 135, 2970.

23. Sangster, A. W.; Stuart, K. L.; Chem. Rev. 1965, 65, 69.

24. Costa, E. V.; Sampaio, M. F. C.; Salvador, M. J.; Nepel, A.; Barison, A.; Quim. Nova 2015, 38, 769.

25. Park, H. J.; Baek, M. Y.; Cho, J. G.; Seo, K. H.; Lee, G. Y.; Moon, S. J.; Ahn, E. M.; Baek, N. I.; J. Korean Soc. Appl. Biol. Chem. 2011, 54, 345.

26. Yang, K.; Jin, G.; Wu, J.; Curr. Neuropharmacol. 2007, 5, 289.

27. Jin, G. Z.; Zhu, Z. T.; Fu, Y.; Trends Pharmacol. Sci. 2002, 23 , 4.

28. Xu, W.; Wang, Y.; Ma, Z.; Chiu, Y. T.; Huang, P.; Rasakham, K.; Unterwald, E.; Lee, D. Y. W.; Chen, L. Y. L.; Drug Alcohol Depend. 2013, 133, 693.

Submitted: November 30, 2018 Published online: June 5, 2019 